\title{
ÉSQUILO: DRAMATURGIA E REPERTÓRIO UMA DISCUSSÃO PRELIMINAR
}

\author{
Marcus Mota* \\ Recebido em: 15/08/2018 \\ Aprovado em: 20/11/2018
}

RESUMO: A análise do número de obras atribuídas a Ésquilo possibilita a compreensão de algumas tendências tanto em sua dramaturgia em particular, quanto no teatro grego da primeira metade do século V a.C. Entre elas, há a exploração de questões de gênero, identidade cultural e hibridismo cênico.

PALAVRAS-CHAVE: Ésquilo; dramaturgia; teatro grego; repertório.
$*$ Diretor do

Laboratório de

Dramaturgia, Universidade de Brasília. Professor do PPG em Metafísica e do PPG em Artes Cênicas, Universidade de Brasília.

marcusmotaunb@ gmail.com

\begin{abstract}
The analysis of the plays that were attributed to Aeschylus enable us to understand some tendencies both in his dramaturgy and in the Ancient Greek Theatre. Among them, there are the exploration of questions of gender, cultural identity, and theatrical hybridity.
\end{abstract}

KEYWORDS: Aeschylus; dramaturgy; Greek theatre; repertoire.

\section{INTRODUÇÃO}

motivação deste artigo advém de um novo boom bibliográfico
em torno dos estudos da dramaturgia ateniense antiga e,
dentro desses títulos, um incremento de publicações em torno de Ésquilo. A renovação dos estudos da dramaturgia ateniense antiga encontrou na clássica obra de Oliver Taplin sobre Ésquilo, publicada há mais de 40 anos, um de seus pontos de partida. Em The Stagecraft of Aeschylus, de 1977, Taplin aproximava a discussão da textualidade da tragédia grega de Ésquilo de modos de leitura e interpretação de textos teatrais desenvolvidos principalmente 
em análises das peças de Shakespeare. ${ }^{1}$ Nesse sentido, ao deslocar essas abordagens que aproximavam textos de seus contextos de performance e produção para o teatro grego, Taplin passa a discutir a materialidade da cena inscrita no texto e na tradição teatral, ao invés de se debruçar sobre temas consagrados, como a psicologia das personagens e seus embates morais. Ou seja, a partir do momento em que Taplin encara as figuras do texto como elaborações de estratégias que não são inteiramente linguísticas, mas pertencentes a um espetáculo, ele habilitou-se a desenvolver análises detalhadas de uma dramaturgia em processo, fruto de escolhas a partir de um conjunto de convenções ou práticas estabelecidas.

Embora em suas análises Taplin tenha se restringido mais às partes não cantadas e dançadas da dramaturgia ateniense, seu ato de aproximar filologia e estudos teatrais providenciou uma abertura fundamental para pesquisadores e artistas interessados tanto na compreensão dos procedimentos dessa dramaturgia, quanto na apropriação e transformação desses procedimentos em novos projetos interartísticos.

O novo boom bibliográfico dialoga com o esforço pioneiro de Taplin e o amplia, ratificando não apenas a dimensão performativa dos textos, mas também a de toda a cultura helênica, como se vê, por exemplo, nas pesquisas de Peter Wilson sobre khoregia ou liturgia em torno da produção do teatro; de Claude Calame sobre a complexidade enunciativa dos mitos; e nos Estudos da Recepção, liderados por um grupo de pesquisadores a partir de Edith Hall. ${ }^{2}$

Dentro desse paradigma ampliado, que correlaciona texto e performance, Ésquilo tem sido alvo de maiores análises. Além de duas novas edições de suas obras - as de WEST, 1998 e de SOMMERSTEIN, 2008 -, temos a seguinte tabela: ${ }^{3}$

TABELA 1 - Recentes publicações em torno de Ésquilo

\begin{tabular}{l|c|c}
\hline \multicolumn{1}{c|}{ Autor } & Ano & País \\
\hline T. ROSENMEYER & 1982 & EUA \\
\hline J. HERINGTON & 1986 & EUA \\
\hline A. SOMMERSTEIN & 1996 & Itália (em inglês) \\
\hline M. F. SOUSA E SILVA & 2005 & Portugal \\
\hline S. FÖLLINGER & 2009 & Alemanha \\
\hline A. F. GARVIE & 2013 & Inglaterra \\
\hline F. DUPONT & 2015 & Suíça \\
\hline CONSTANTINIDIS & 2016 & Holanda \\
\hline M. McALL & 2017 & Inglaterra \\
\hline
\end{tabular}

\footnotetext{
${ }^{1}$ Ver Taplin, 1977. Sobre a avaliação das contribuições de O. Taplin, v. Revermann; Wilson, 2008.

${ }^{2}$ Ver, respectivamente, Wilson, 2003; Calame, 1986; Hall; Harrop, 2010. Para uma análise de outros autores desse boom, v. Mota, 2008, p. 23-50; Mota, 2014. Para pressupostos da cultura performativa, ver Mota, 2018.

${ }^{3}$ As publicações indicadas são uma amostra, com foco em introduções ao dramaturgo. Para uma lista mais completa, v. Mota, 2008, p. 497-522; Torrance, 2010.
} 
Esta seleção de publicações ratifica a percepção da convergência entre uma maior aproximação de aspectos performativos dos textos clássicos e uma maior presença ou visibilidade de Ésquilo. A partir dessa aproximação, há novos pressupostos, novas possibilidades de se interrogar a dramaturgia de Ésquilo. Neste artigo, foram selecionadas três dessas possibilidades, que serão indicadas abaixo, junto com a sugestão de uma bibliografia para seu acompanhamento. Com isso, objetivou-se apontar para temas e abordagens não muito usuais dentro da recepção de Ésquilo, as quais impulsionariam investigações mais detalhadas no futuro. Em suma, este artigo parte de um ambiente intelectual em extensão, procura captar algumas tendências e oferecer a estudiosos e interessados referências e reflexões para futuros empreendimentos. ${ }^{4}$

\section{NúMERO E NOMES}

Não se sabe exatamente quantas peças Ésquilo elaborou e encenou. As fontes de informação que nos chegaram propõem diversos números. ${ }^{5}$ Disponibilizamos aqui os títulos de 81 obras, de um total de 90 que convencionalmente são atribuídas ao dramaturgo, o que resulta em um catálogo com $90 \%$ dos títulos das peças de Ésquilo. Potencialmente, teríamos 22 trilogias $(4 \times 22=88)$. Com texto completo, porém, restaram apenas 6 tragédias, que vão marcadas em negrito na lista que se segue abaixo.

Nesta lista, os títulos das obras estão ordenados em dois grupos: primeiro, os conjuntos de tetralogias ou peças conectadas, marca da produção dramatúrgica de Ésquilo. ${ }^{6}$ Destacamos as tetralogias que possuem maior documentação. Em seguida, elencamos os títulos individualmente.

A razão dessa opção reside no fato de que, além das 6 peças que indiscutivelmente são de autoria de Ésquilo, o que temos são fragmentos - ou só títulos - das demais obras, as quais foram citadas por outros autores. Às vezes nem isso: apenas o título das obras.

\section{A. Tetralogias}

\section{Fineu, Os Persas, Glauco Potnieu, Prometeu acendedor do fogo;}

2. Laio, Édipo, Sete contra Tebas, Esfinge;

3. As Suplicantes, Os Egipcios, As Danaides, Amimone;

\footnotetext{
${ }^{4}$ Recentemente, realizamos a mesma proposta no levantamento de questões básicas para a materialidade audiovisual do Teatro de Dioniso (Mota, 2017).

${ }^{5}$ Para os números, há referências no Suda (90 obras) e no Vida de Ésquilo (75 obras). No manuscrito Mediceus, há um catálogo de títulos de obras atribuídas a Ésquilo (73 itens). Além disso, a tradição indireta inclui mais nove títulos não referidos neste catálogo. Para uma discussão das fontes, que não é o foco deste artigo, ver Mette, 1963; Wartelle, 1971, p. 19-39; Gantz, 1980a; Sommerstein, 1996, p. 27-32; Martel, 1999, p. IX-LXI; Radt, 2009, p. 31-108; Ramelli, 2009, p. 7-23; Sommerstein, 2008; Lucas de Dios, 2008, p. 12-6; Sommerstein, 2010, p. 11-29.

${ }^{6}$ Tetralogias podem ser tematicamente conectadas ou não. Há uma predominância do primeiro tipo em Ésquilo (Gantz, 1980; Sommerstein, 1996, p. 53-70).
} 
4. Agamêmnon, Coéforas, Eumênides, Proteu $\{\text { Oresteia }\}^{7}$;

5. Edônios, As Bassarides, Os Jovens, Licurgo \{Licurgia $\}^{8}$;

6. Mirmidões, Frígios (ou O resgate de Heitor $\left.{ }^{9}\right)$, Nereidas, $\left(\mathrm{xxxxx}^{10}\right)\{$ Aquileida\};

7. Psicagogos, Penélope, Recolhedores de ossos, Circe.

Total até aqui: 27 peças.

B. Títulos individuais

28. Alcmena

29. Arautos

30. Argo (ou Os Remadores)

31. As Arqueiras

32. Atalanta

33. Atamante

34. Cabiros

35. Calisto

36. As Cardadeiras $\{$ Xantriai $\}$

37. Cários (ou Europa)

38. Cercião

39. Cisne $\{$ Kyknos $\}$

40. O Cortejo $\{$ Propompoi $\}$

41. As Cretenses

42. As Cuidadoras de Dioniso \{Trophoi\}

43. Os Epígonos

44. Filoctetes

45. Filhos de Héracles

46. Filhas do Sol \{Heliades\}

47. Filhas de Fórcis $\{$ Phorkides\}

48. Glauco, o deus marinho \{Glaukos Pontios\}

49. Eleusinos

50. Hipsipile

\footnotetext{
${ }^{7}$ Nesta lista, adotamos os colchetes para indicar: a) uma informação extra, como o nome da tetralogia à qual o conjunto de obras pertence; b) a transliteração do título original grego da obra.

${ }^{8}$ West, 1990a, p. 26-50.

${ }^{9}$ Algumas peças possuem mais de um título. Marca-se aqui o fato com parênteses.

${ }^{10} \mathrm{O}$ título do drama satírico desta tetralogia é desconhecido.
} 
51. Ifigênia

52. Íxion

53. O Julgamento da armas

54. O Leão

55. Os Misios

56. Mêmnon

57. Mulheres de Argos $\{$ Argeiai $\}$

58. Mulheres/Ninfas de Etna (Aitnaiai)

59. Mulheres da Frígia $\{$ Phrugiai $\}$

60. Mulheres de Lemnos \{Lemniai\}

61. Mulheres da Perrébia \{Perrhaibides\}

62. Mulheres de Salamina \{Salaminiai\}

63. Mulberes da Trácia

64. Neméia

65. Niobe

66. Oritia

67. Os Obreiros/construtores da câmara nupcial \{Thalamopoioi\}

68. Palamedes

69. Penélope

70. Penteu

71. Os Pescadores (com redes)/ Os fabricantes de redes $\{$ Dik.tyoulkoi\}

72. Psicostasia / Pesagem das almas

73. Polidetes

74. Prometeu acorrentado ??? 11

75. Prometeu liberto

76. As Sacerdotisas $\{$ Hiereiai $\}$

77. Sagrada comitiva (ou Nos Jogos Ístmicos) \{Theoroi ou Isthmiastai\}

78. Sêmele (ou Mulheres que carregam vasos de água)

79. Sísifo fugitivo

80. Sisifo rolador de pedra

81. Télefo

\footnotetext{
${ }^{11}$ Mesmo atribuída tradicionalmente a Ésquilo, parece, segundo estudos mais recentes, ter sido obra tardia, de alguém vinculado a Ésquilo (Griffith, 1977, 1983). Em razão disso, a posição aqui adotada é que se trata de uma questão em suspenso.
} 


\section{GÊNEROS EM CONFLITO}

Analisando a lista, podemos identificar um grupo de peças que possuem como título grupos de agentes femininos e regiões: 1. Coéforas (As portadoras de libações), 2. Eumênides (As Benévolas), 3. As Suplicantes, 4-5. As Danaides, 6. As Bassarides, 7. As Nereidas, 8. As Arqueiras, 9. As Cardadeiras, 10. As Cuidadoras de Dioniso, 11. Filhas do Sol, 12. Filhas de Fórcis, 13. As Sacerdotisas, 14. Mulheres que carregam vasos de água, 15. As Cretenses, 16. Penélope, 17. Mulheres de Argos, 18. Mulheres/Ninfas de Etna, 19. Mulheres da Frígia, 20. Mulheres de Lemnos, 21. Mulheres da Perrébia, 22. Mulheres de Salamina, 23. Mulheres da Trácia, num total de 23 ocorrências, o que dá uma porcentagem de quase um terço dos títulos restantes (28.395\%).

Se tomarmos como exemplo as peças com textos completos que temos - Coéforas, Eumenides, As Suplicantes - tais títulos de coletivos femininos não apenas demonstram o papel do coro nessas peças, e por extensão, nos dramas de Ésquilo, como também as tensões de gênero ali decorrentes. Nas análises das peças individuais ficará mais claro o modo pelo qual Ésquilo explora em sua dramaturgia construções do masculino e sua relação com o feminino.

Em contraste a esse extranumerário de coletivos femininos, temos o seguinte número de coletivos masculinos nos títulos: 1. Sete contra Tebas, 2. Os Jovens, 3. Psicagogos, 4. Recolhedores de ossos, 5. Arautos, 6. O Cortejo, 7. Os Obreiros/construtores da camara nupcial, 8. Os Epigonos, 9. Filhos de Héracles, 10. Os Misios, 11. Cários, 12. Eleusinos, 13. Os Persas, 14. Edônios, 15. Frígios, 16. Cabiros, 17. Os Egipcios, 18. Mirmidões, 19. Os Pescadores (com redes)/ Osfabricantes de redes, 20. Sagrada comitiva ou Nos Jogos Ístmicos, o que nos leva a mais de um quarto das peças restantes $(24.691 \%)$. Ora, reunindo os números relativos a títulos que se referem a grupos por função ou coletivos étnicos, vemos que mais da metade das obras referidas $(53.086 \%)$ possuem por título o coro.

Tais números reafirmam aquilo que podemos observar nas seis peças restantes de Ésquilo. Em uma contagem dos versos que não são cantados e dançados nessas seis peças, temos a seguinte distribuição: ${ }^{12}$

TABELA 2 - Número de versos das peças de Ésquilo

\begin{tabular}{l|c|c|c}
\hline \multicolumn{1}{c|}{ Título } & Total de versos & Versos falados & Porcentagem \\
\hline Os Persas & 1077 & 429 & $39.832 \%(40 \%)$ \\
\hline Sete contra Tebas & 1078 & 475 & $44.063 \%(44 \%)$ \\
\hline Suplicantes & 1073 & 473 & $44.082 \%(44 \%)$ \\
\hline Agamêmnon & 1673 & 844 & $50.448 \%(50 \%)$ \\
\hline Coéforas & 1076 & 620 & $57.620 \%(57 \%)$ \\
\hline Eumênides & 1047 & 640 & $61.127 \%(61 \%)$ \\
\hline
\end{tabular}

\footnotetext{
${ }^{12}$ Dados referentes ao número de trímetros iâmbicos ou versos falados foram retirados de Stinton (1977, p. 71). Esses números também rearfirmam as dimensões temporais assemelhadas das peças, indicando haver a possibilidade de um limite de duração dos espetáculos.
} 
Vemos até a Oresteia um padrão: mais da metade do número total de versos das peças são de atividade do coro. Mas é preciso ter em mente que os versos falados não excluem a atividade do coro: o coro/corifeu dialoga com os agentes não corais. Em Ésquilo, pelo menos nas peças restantes, isso é mais comum que o inverso: vemos maior participação do coro na contracenação verbal com os outros agentes não corais, do que agentes não corais exercendo atividades do coro - canto/dança. Isso também ficará mais claro na análise das peças individuais. De qualquer forma, os títulos das obras e as proporções entre versos falados e cantados/dançados nos remetem a uma ampla presença do coro na dramaturgia de Ésquilo.

\section{IDENTIDADES CULTURAIS}

O outro aspecto dos grupos corais é o da 'cor local' ou referência topográfica: os títulos evocam diversas regiões e/ou povos. Essa dramaturgia 'globalizada' marca um momento único na arte teatral da cosmopolita Atenas que, depois de Ésquilo, se modificará: o foco das atenções será cada vez mais a cidade mesma e seus problemas domésticos. ${ }^{13}$

Para bem esclarecer esta dramaturgia que negocia amplas fronteiras geográficas e culturais, cito as palavras de John Herington:

três quartos dos títulos e fragmentos de peças nos inserem em uma selvagem paisagem de mitos que parece não ter limites de tempo, espaço ou credibilidade - uma antiquíssima paisagem que poucos dramaturgos europeus posteriores, mesmo os dramaturgos atenienses, foram explorar alguma vez em cena. (...) É uma paisagem rica em magia - um tipo de magia que, muito tempo depois, Antonin Artaud almejava para seu teatro ideal. ${ }^{14}$ Não apenas Tebas e as planícies de Argos e Troia, mas o espaço do Mediterrâneo oriental todo é passível de ser observado, povoado densamente com seus heróis e heroínas lendárias. Muitos deles perpetuaram a memória de dinastias minoicas e micênicas, que viveram e reinaram em diversas cidades e ilhas antes do colapso das civilizações da Idade do Bronze (Herington, 1986, p. 49-50). ${ }^{15}$

A seguinte tabela procura elencar os títulos e suas áreas geoculturais:

\footnotetext{
${ }^{13}$ Daí se compreende o uso de catálogos de lugares e pessoas como, por exemplo, em Os Persas, As Suplicantes, Agamêmnon e Eumênides. Essa geografia encenada maravilhava os ouvintes, ampliando o espaço de cena e a imaginação da audiência (Bernard, 2005; Kennedy, 2006; Rose, 2009; Bianchetti, 2009). Agradeço à profa. Serena Bianchetti pelo gentil envio de seu artigo.

${ }^{14}$ Para a dimensão remota dessa dramaturgia, Deforge, 2008. Correlato do entrechoque de mundos é o entrechoque de línguas, como vemos em Os Persas, As Suplicantes e a personagem Cassandra, em Agamêmnon. Sobre o tema das línguas em contato em uma encenação, por uma ótica contemporânea, Carlson, 2006.

${ }^{15}$ Situado entre 1200 e 1150 a.C.
} 
TABELA 3 - Áreas geoculturais

\begin{tabular}{l|l}
\hline \multicolumn{1}{c|}{ Espaço } & \multicolumn{1}{c}{ Peças } \\
\hline Coríntia & Sísifo Fugitivo, Sísifo rolador de pedra \\
\hline Beócia & Atamante, Calisto \\
\hline Arcádia -Tessália & Atalanta, Ixion, Mulheres da Perrébia \\
\hline Sić́lia & As Mulheres/Ninfas de Etna \\
\hline Ilha de Creta & Cários, As Cretenses \\
\hline Egito/Líbia & Proteu, Filhas de Fórcis \\
\hline Trácia & Edônios, As Bassarides, Os Jovens, Licurgo, Mulheres da Trácia \\
\hline Ilhas de Samotrácia e Lemnos & Mulheres de Lemnos, Hipsípile, Cabiros, Argo, Filoctetes \\
\hline Mar Negro/Ponto Euxino/Ásia Menor & Fineu, Mulheres da Frígia \\
\hline
\end{tabular}

\section{Hibridismo CÊNICO}

Outro tema a considerar no catálogo de títulos de Ésquilo é um conjunto de peças chamadas 'dramas satíricos', que são as obras que fecham as tetralogias. ${ }^{16}$ Nada além dos títulos, referências e alguns trechos foi o que sobrou desse tipo de dramaturgia de Ésquilo. Ora, se a cada quatro peças uma era drama satírico, Ésquilo teria escrito pelo menos 22 deles. Com maior grau de certeza, temos os seguinte títulos: 1. Prometeu acendedor do fogo, 2. Esfinge, 3. Amimone, 4. Proteu, 5. Licurgo, pois dizem respeito às tetralogias sobre as quais temos informações mais precisas. ${ }^{17}$

Juntam-se a essa lista, em virtude do conteúdo dos fragmentos e referências na transmissão textual, os seguintes títulos: 6. Glauco marinho, 7. Os Pescadores com redes, 8. Sagrada comitiva ou Nos Jogos Ístmicos, 9. Cercião, 10. Arautos, 11. Circe, 12. O Leão, 13. Calisto, 14. Cabiros, 15. Sísifo rolador de pedra, 16. As Cuidadoras de Dioniso.

O que define um drama satírico, inicialmente, não é a sátira, mas a presença de um grupo de sátiros, o coro da peça. Essas figuras ambivalentes, meio humanas, meio bestas, formam o bando que acompanha um líder. ${ }^{18}$ Neste tipo de espetáculo, Ésquilo poderia se valer de uma linguagem menos estilizada, como a que usava em suas tragédias. Além disso, outras emoções estariam envolvidas: frequentemente, os sátiros oscilam entre desejos baixo-corporais e estupor diante de algo fora do comum. Os sátiros são seguidores, estão disponíveis a serem subordinados. $\mathrm{E}$ as limitações emotivas e cognitivas dessa funcionalidade dramática impelem excessos e contrassensos em seus comportamentos.

${ }^{16}$ Ussher, 1977; Sutton, 1974, 1980; Sousa e Silva, 2005, p. 167-72; Podlecki, 2005; Lämle, 2011; Sansone, 2015; Borowski, 2015.

${ }^{17}$ Gantz, 1980; Sommerstein, 1996, p. 70.

${ }^{18}$ Note-se a presença de um bestiário, de nomes de animais ou criaturas animalizadas nos títulos, como O Leão, A Esfinge, Cisne. 
A estas marcas dos híbridos sátiros, ajunte-se o limite temporal: as peças possuem uma menor duração. ${ }^{19}$ Disso, dessa intensidade no tempo, segue-se que os drama satíricos apresentam muito mais ações físicas que as tragédias, alargando as possibilidades do universo imaginativo encenado. Assim, há espaço para danças frenéticas, correrias, gritarias, entre outros atos, que acabam por chamar atenção para si mesmo, para a própria performance. Como veremos, a área de atuação que a dramaturgia de Ésquilo aponta dialoga com eventos fora de cena. Os agentes em cena contracenam com eventos que são comentados, trazidos para cena por outros agentes e por suas memórias. ${ }^{20} \mathrm{O}$ drama satírico, por sua vez, traz um senso de atualidade, relacionado ao anti-heroísmo, ou mundo às avessas de suas figuras míticas. Mais propriamente, os seguidores de Dioniso são transpostos para situações liminares, nas quais se defrontam a lógica do mito e os contextos mais cotidianos. O entrechoque entre lógicas, ordens e contextos produziria estranhamento e comicidade. Nesse sentido, o 'Ésquilo trágico' se complementaria com o 'Ésquilo dos Sátiros': as diversas perspectivas que as tragédias oferecem diante de dilemas éticos de suas figuras encontrariam nos cantos e danças de Dioniso sua celebração.

Essa complementaridade entre a tragédia e o drama satírico é patente no modo de agrupar as tetralogias: segundo a lista de títulos supracitada, percebemos que o material do drama satírico se relaciona com a trilogia trágica. As quatro peças guardam relação entre si, formando um conjunto de algum modo integrado e interrelacionado.

Dessa forma, compor tragédias é de algum modo também compor dramas satíricos e vice-versa. Como cada dramaturgo prepara e encena um grupo de quatro peças, ele se vale do mesmo elenco para realizar a tetralogia e a apresenta para o mesmo público. ${ }^{21} \mathrm{O}$ processo criativo é temporalmente comum e a ocasião de performance a mesma. Tanto que um gramático do século 4 a.C. , Demétrio de Falero, afirmou que o drama satírico é uma espécie de 'tragédia lúdica' ( $\tau \rho \alpha \gamma \omega \delta i ́ \alpha \pi \alpha i \zeta o v \sigma \alpha^{22}$ ) - uma tragédia que brinca e diverte -, demonstrando o íntimo vínculo que possuem entre si.

Pelos títulos das tetralogias conectadas, os dramas satíricos se refeririam a eventos próximos ou anteriores à primeira peça, o que indica, pela fratura temporal, a possibilidade de colocar em cena tanto uma revisão daquilo que é o material das tragédias, quanto focar em algo que não foi apresentado, ou evitado. ${ }^{23} \mathrm{~A}$ partir disso, podemos então pensar que a tragédia e o drama satírico efetivam um jogo de similaridades e diferenças, o que corrigiria muitas de nossas ideias sobre o que seria a tragédia e a dramaturgia ateniense.

\footnotetext{
${ }^{19}$ Deduz-se pelas dimensões do único drama satírico restante, O Ciclope, de Eurípides. Ou seja, uma aproximação entre o número de versos, no caso 709, e o tempo possível de sua performance. Comparando com os textos das tragédias de Ésquilo as quais, com exceção de Agamêmnon, ficam entre 1047 e 1077 versos, temos que O Ciclope tem as dimensões de aproximadamente 66\% de uma tragédia. ${ }^{20}$ Stanchi, 2007.

${ }^{21}$ Griffith, 2002, p. 196. Ainda a partir de O Ciclope, vemos que um drama satírico compartilha com a tragédia a mesma divisão e distribuição de partes cantadas/dançadas e partes não corais.

22 De Elocutione, 169. Sigo edição de Fortenbaugh; Schütrumpf, 2000.

${ }^{23}$ Famosa "lei de Levi" (Sansone, 2015, p. 30).
} 
Ora, se o dramaturgo é envolvido em um processo criativo que culmina na produção de quatro espetáculos conectados, essas conexões não são apenas temáticas. A última não é um adendo, mas encerra todo o processo criativo, dialogando com o material e com a definição de espetáculo ali realizada. Se há este diálogo, começamos a ir além de uma pureza abstrata de gêneros - onde, supostamente, a tragédia seria o que o drama satírico não é; onde a tragédia não teria traços do drama satírico. Valendo o mesmo, inversamente, para o drama satírico.

Em certo sentido isso é correto: na tragédia, não temos coros de sátiros e as ações são mais ritualizadas, formalizadas. Mas isso não significa que não haja comicidade, ou melhor, que durante uma tragédia se produza um estado emocional único, característico e dominante em toda a apresentação. E, mais ainda, que as figuras na tragédia não apresentem comportamentos aberrantes, atos ou palavras relacionados ao 'baixo corporal'. ${ }^{24} \mathrm{Ou}$ ainda mais: que os agentes estrangeiros com suas falas e caracterização não sejam alvo de efeitos de estranhamento e, disto, comicidade. ${ }^{25}$

Da mesma maneira, no drama satírico temos agentes dramáticos que não se reduzem a agir maliciosamente. A dimensão híbrida das figuras e os cenários fora dos ambientes urbanos (rurais ou nas margens das águas) nos remetem para uma problemática que a tensão e complementaridade entre tragédia e drama satírico cifra: o lugar de Ésquilo dentro da tradição teatral ateniense, e daí, de Ésquilo para a dramaturgia ocidental. O viajante e geógrafo Pausânias (110-180 d.C) registra um inusitado comentário ao visitar a tumba do dramaturgo Aristias, cujo pai foi Prátinas, também dramaturgo e contemporâneo de Ésquilo e tido como introdutor dos dramas satíricos nas Grandes Dionísias: “Aqui também está a tumba de Aristias, filho de Prátinas. Este Aristias e seu pai Prátinas compuseram dramas satíricos os mais bem aprovados pelo público, salvo os compostos por Ésquilo". ${ }^{26}$ É surpreendente que 600 anos depois de sua morte Ésquilo seja lembrando não apenas pela popularidade de suas tragédias, tendo se tornado proverbial sua maestria em explorar as possibilidades e efeitos do hibridismo do drama satírico. ${ }^{27}$

Assim, fica para nós, por enquanto, a imagem de um dramaturgo que intervém em uma tradição teatral pré-existente, ela mesma heterogênea, formada a partir de diversas tradições performativas, como as do rapsodo homérico e dos cantos corais, entre outras, para redirecioná-la, dar-lhe um novo padrão, como no caso de trilogias/tetralogias conectadas, mas,

\footnotetext{
${ }^{24}$ Termo relacionado à análise de M. Bakhtin da poética de François Rabelais, que abunda em referências à fisiologia corporal e a atos como comer, beber, fazer sexo, respirar, vomitar, etc. (Bakhtin, 1987). Sobre as ocorrências de comicidade na linguagem em Ésquilo, Sommerstein, 2002. Sobre matizes coloquiais na linguagem de Ésquilo, Stevens, 1945 e West, 2013.

${ }^{25}$ Bacon, 1961.

${ }^{26}$ Pausânias, Descrição da Grécia 2.13.6. Sigo edição Loeb.

${ }^{27}$ Diógenes Láercio, no século III de nossa era, também registra em sua Vidas e Doutrinas dos Filósofos Ilustres (II, 133) que Ésquilo era o primeiro dentre os que compuseram dramas satíricos. Sigo edição de Dorandi, 2013.
} 
ao mesmo tempo, e em decorrência disso, trabalhar ainda nas fronteiras, na experimentação, na pesquisa expressiva, na inovação. ${ }^{28}$

\section{CONCLUSÃo}

Uma análise da lista de obras restantes de Ésquilo projeta uma imagem complexa tanto da carreira do dramaturgo quanto da dramaturgia ateniense. Pode-se perceber que a proposição e encenação de obras cenicamente orientadas dialogavam com um imenso campo de possibilidades de experimentação estética e social. A instabilidade de uma cidade em reconstrução durante as invasões persas apresenta-se rediscutida e reelaborada por espetáculos que colocam frente a frente figuras, línguas, imagens e sons de diversos lugares da área mediterrânea.

As análises aqui efetivadas são preliminares: distinguem temas para futuras investigações que venham a enfrentar a lacunaridade da tradição teatral ateniense e seu contexto plural de instituições e práticas. Em todo caso, demonstra-se que a consideração de uma lista de obras, ou repertório, mesmo que em suas limitações recepcionais, fornece rico material para o estudo da dramaturgia ateniense clássica.

\section{REFERÊNCIAS}

BACON, H. Barbarians in Greek Tragedy. New Haven: Yale University Press, 1961.

BAKHTIN, M. A cultura popular na Idade Média e no Renascimento: o contexto de François Rabelais. São Paulo: Hucitec, 1997.

BERNARD, A. La carte du tragique. La géographie dans la tragédie grecque. Paris: Éditions du CNRS, 1985.

BIANCHET'TI, S. La geografia delle Supplici di Eschilo come immagine dei valori della polis ateniese. Sileno, v. 35, p. 117-28, 2009.

BOROWSKI, Y. Laughter in Ancient Greek Drama of the Classical Period. Tragedy and Satyr Play. 2015. Tese (PhD) - Universidade de Łódź (Polônia), 2015.

Disponível em: <http://dspace.uni.lodz.pl/xmlui/bitstream/handle/11089/11865/ Yvonne $\% 20$ Borowski $\% 20-\% 20 \mathrm{PhD} \%$ 20thesis.pdf? sequence $=1$ \&is Allowed $=\mathrm{y}>$.

CALAME, C. Le Récit en Grèce ancienne. Énonciations et représentations de poètes. Paris: Klincksieck, 1986.

\footnotetext{
${ }^{28}$ Griffith, 2009, p. 6, enumera as seguintes relações intertextuais de Ésquilo com tradições prévias: narrativa épica homérica; poesia didática/gnômica/parenética, isto é, 'sabedoria tradicional'; poesia lírica coral celebratória e monódica/simposial; atos de fala de rituais não literários (orações, encantamentos, maldições, magia); discursos da ciência etnográfica pré-socrática, incluindo medicina, direito, política e retórica. Ver ainda Palladini, 2001. Para a relação entre tragédia e comédia, ver Csapo, 2010, 2015; Shaw, 2014.
} 
CARLSON, M. Speaking in Tongues: Language at Play in the Theatre. Michigan: University of Michigan Press, 2006.

CONSTANTINIDIS, S. (Org.) The Reception of Aeschylus Plays Through Shifting Models and Frontiers. Leiden: Brill, 2016.

CSAPO, E. The Earliest Phase of 'Comic' Choral Entertainments in Athens: The Dionysian Pompe and the 'Birth' of Comedy. In: CHRONOPOULOS, C. S.; ORTH, C. (Ed.). Fragmente einer Geschichte der griechischen Komödie / Fragmentary History of Greek Comedy. Heidelberg: Verlag Antike, 2015. (Studia Comica, 5)

CSAPO, E. The Production and Performance of Comedy in Antiquity. In: DOBROV, G. W. (Ed.). Brill's Companion to the Study of Greek Comedy. Leiden: Brill, 2010.

DEFORGE, B. La Grèce ancienne: héritage et devenir des pensées mythico-symboliques du monde méditerranéen : le rôle crucial et méconnu d'Eschyle. Bulletin de l'Association Guillaume Budé, v. 2, p. 19-36, 2008.

DORANDI, T. Diogenes Laertius. Lives of Eminent Philosophers. Oxford: Cambridge University Press, 2013.

DUPONT, F. Eschyle. Lausane: Ides et Calendes, 2015.

FÖLLINGER, S. Aischylos. Meister der griechischen Tragödie. Munich: C. H. Beck, 2009.

FORTENBAUGH, W.; SCHÜTRUMPF, E. (Ed.). Demetrius of Phalerum. Text, Translation, and Discussion. New Brunswick: Transaction Publishers, 2000.

GANTZ, T. Aischylos' Lost Plays: The Fifth Column. Rheinisches Museum für Philologie, v. 123, n. 3/4, p. 210-222, 1980a.

GANTZ, T. The Aischylean Tetralogy: Attested and Conjectured Groups. The American Journal of Philology, v. 101, p. 133-64, 1980.

GARVIE, A.F. The Plays of Aeschylus. Bristol: Bristol Classical Press, 2013.

GRIfFITH, M. Aeschylus. Prometheus Bound. Oxford: Cambridge University Press, 1983.

GRIFFITH, M. The poetry of Aeschylus (In its Traditional Contexts). In: JOUANNA, J; MONTANARI, F; HERNÁNDEZ, A-C. (Org.). Eschyle à l'aube du théâtre occidental: neuf exposés suivis de discussions. Genève: Fondation Hardt, 2009. p. 1-55.

GRIFFITH, M. The Authenticity of Prometheus Bound. Oxford: Cambridge University Press, 1977.

HALL, E.; HARROP, W. Theorising Performance. Greek Drama, Cultural History and Critical Practice. Londres: Bloomsbury, 2010.

HERINGTON, J. Aeschylus. New Haven: Yale University Press, 1986.

KENNEDY, R. F. (Org.). Brill's Companion to the Reception of Aeschylus. Leiden: Brill, 2018. 
KENNEDY, R.F. Justice, Geography and Empire in Aeschylus' Eumenides. Classical Antiquity, v. 25, n. 1, p. 35-72, 2006.

LÄMMLE, R. Poetik des Satysrpiels. Heidelberg: Universitätsverlag Winter, 2013.

LUCAS DE DIOS, J. M. Esquilo. Fragmentos: Testimonios. Madrid: Gredos, 2008.

MARTEL, J. M. Semántica y hermeneútica em las glosas y escolios de las tragedias de Esquilo. 1999. Tese (Doutorado) - Universidad de La Laguna, 1999.

McCALL, M. Aeschylus. Blackwell Introductions to the Classical World. Hoboken: WileyBlackwell, 2017.

METTE, H.J. Der verlorene Aischylus. Berlin: Akademie-Verlag, 1963.

MOTA, M. A performance como argumento: discussão de conceitos básicos a partir da teatralidade para a compreensão da produção textual na Grécia Antiga. In: SOARES, C.; BRANDÃO, J. L.; CARVALHO, P. (Org.). História Antiga: Relações Interdisciplinares. Fontes, Artes, Filosofia, Política, Religião e Recep̧ão. Coimbra: Imprensa da Universidade de Coimbra, 2018. p. 165-82.

MOTA, M. Teatro Grego: Novas Perspectivas. In: CORNELLI, G.; COSTA, G. (Org.). Estudos Clássicos. Cinema, Literatura,Teatro e Arte. São Paulo: Annablume, 2014. p. 85-106.

MOTA, M. A dramaturgia musical de Ésquilo. Brasília: Universidade de Brasília, 2008.

MOTA, M. Introdução à dramaturgia ateniense: espaço, som e organização textual. Dramaturgia em Foco, v. 1, p. 78-95, 2017.

PALLADINI, L. Traces of 'Intellectualism' in Aeschylus, Hermes, v. 129, p. 331-458, 2001.

PAUSANIAS. Description of Greece. Cambridge: Loeb Classical Library; Harvard University Press, 1934.

PODLECKI, A. Aiskhylos Satyrikos. In: HARRISON, G. (Org.) Satyr Drama. Tragedy at Play. Swansea: Classical Press of Wales, 2005. p. 1-20.

RADT, S. Tragicorum Graecorum Fragmenta. Vol. III: Aeschylus. Göttingen: Vandenhoeck \& Ruprecht, 2009.

RAMELLI, I. Tutti i frammenti con la prima traduzione degli scolii antichi. Milano: Bompiani, 2009.

REVERMANN, M.; WILSON, P. (Org.). Performance, Iconography, Reception. Studies in Honour of Oliver Taplin. Oxford: Oxford University Press, 2008.

ROSE, P. Aeschylus' Geographic Imagination, Classica, v. 22, n. 2, p. 270-80, 2009. http://doi.org/10.14195/2176-6436_22-2_8

ROSENMEYER, T. The Art of Aeschylus. Oakland: University of California Press, 1982.

SANSONE, D. The Place of the Satyr Play in the Tragic Tetralogy. Prometheus, v. 41, p. 3-36, 2015. 
SHAW, C. Satyric Play: The Evolution of Greek Comedy and Satyr Play. Oxford: Oxford University Press, 2014.

SOMMERSTEIN, A. Aeschyelan Tragedy. Bari: Levante Editori, 1996.

SOMMERSTEIN, A. La tetralogia di Eschilo sulla guerra persiana. Dionysus ex Machine, v. 1, p. 4-20, 2010.

SOMMERSTEIN, A. Aeschylus. Cambridge: Harvard University Press, 2008. 3 v.

SOMMERSTEIN, A. H. Comic elements in tragic language: the case of Aeschylus' Oresteia. In: WILLI, A. (Org.). The Language of Greek Comedy. Oxford: Oxford University Press, 2002. p. 151-68.

SOUSA E SILVA, M. F. Ésquilo. O primeiro dramaturgo europeu. Coimbra: Imprensa da Universidade de Coimbra, 2005.

STANCHI, N. La presenza assente. L'attesa del personaggio fuori scena nella tragedia greca. Milano: LED Edizioni Universitarie, 2007.

STEVENS, P. T. Colloquial Expressions in Aeschylus and Sophocles. Classical Quarterly, v. 39, n. 3/4, p. 95-105, 1945.

STINTON, T. C. W. Interlinear Hiatus in Trimeters. Classical Quarterly, v. 27, n. 1, p. 67-72, 1977.

SUTTON, D. A Handlist of Satyr Plays. Harvard Studies in Classical Philology, v. 78, p. 107-43, 1974.

SUTTON, D. The Greek Satyr Play. Meseinheim am Glan: Hain, 1980.

TAPLIN, O. The Stagecraft of Aeschylus. Oxford: Oxford University Press, 1977.

TORRANCE, I. Aeschylus. Oxford Bibliographies. Oxford: Oxford University Press, 2011.

USSHER, R. G. The Other Aeschylus. A Study of the Fragments of Aeschylean Satyr Plays. Phoenix, v. 31, p. 287-99, 1977.

WARTELLE , A. Histoire du texte d'Eschyle. Paris: Belles Lettres, 1971.

WEST, M. L. Studies in Aeschylus. Stuttgart: B. G. Teubner, 1990a.

WEST, M. L. Colloquialism and Naive Style in Aeschylus. In: WEST, M. L. Hellenica. Selected Papers on Greek Literature and Thought. v. II. Lyric and Drama. Oxford: Oxford University Press, 2013. p. 203-214.

WEST, M. L. Aeschyli Tragoediae: cum incerti poetae Prometheo. Stuttgart: B. G. Teubner, 1990.

WILSON, P. The Athenian Institution of the Khoregia: The Chorus, the City and the Stage. Oxford: Cambridge University Press, 2000. 